\title{
More Than Half Prevalence of Protozoan Parasitic Infections Among Diarrheic Outpatients in Eastern Tigrai, Ethiopia, 2019; A Cross-Sectional Study
}

This article was published in the following Dove Press journal: Infection and Drug Resistance

\author{
Brhane Berhe (D) \\ Fitsum Mardu' \\ Kebede Tesfay' \\ Haftom Legese (iD) ${ }^{2}$ \\ Gebre Adhanom ${ }^{2}$ \\ Hagos Haileslasie (iD) ${ }^{3}$ \\ Gebremedhin Gebremichail (iD ${ }^{3}$ \\ Brhane Tesfanchal ${ }^{4}$ \\ Niguse Shishay ${ }^{5}$ \\ Hadush Negash (iD ${ }^{2}$ \\ 'Unite of Medical Parasitology and \\ Entomology, Department of Medical \\ Laboratory Science, College of Medicine and \\ Health Science, Adigrat University, Adigrat, \\ Tigrai, Ethiopia; ${ }^{2}$ Unite of Medical \\ Microbiology, Department of Medical \\ Laboratory Science, College of Medicine and \\ Health Science, Adigrat University, Adigrat, \\ Tigrai, Ethiopia; ${ }^{3}$ Unite of Hematology and \\ Immuno-Hematology, Department of \\ Medical Laboratory Science, College of \\ Medicine and Health Science, Adigrat \\ University, Adigrat, Tigrai, Ethiopia; ${ }^{4}$ Unite of \\ Clinical Chemistry, Department of Medical \\ Laboratory Science, College of Medicine and \\ Health Science, Adigrat University, Adigrat, \\ Tigrai, Ethiopia; ${ }^{5}$ Unite of Immunology, \\ Department of Medical Laboratory Science, \\ Adigrat University, Adigrat, Tigrai, Ethiopia
}

Correspondence: Brhane Berhe

Adigrat, Tigrai, Ethiopia

Tel +25I-9-2I-89-19-16

Fax +25। 344452170

Email birhaneberhe54@gmail.com
Background: Protozoan infections remain a major public health concern in Ethiopia, which causes malnutrition, protein and iron deficiencies, increment of health costs, hospitalization and long-term deleterious effects. In Tigrai, particularly, in the study area, there are limited literatures on the prevalence of protozoa and associated factors among diarrheic outpatients. Thus, aimed to determine the prevalence and associated factors of protozoan infections among diarrheic outpatients in Eastern Tigrai.

Methods: Health facility-based cross-sectional study was conducted in Eastern Tigrai, Ethiopia from April to October 2019 among diarrheic outpatient in health facilities of Adigrat. Four hundred one eighteen study participants were included consecutively. The stool samples were examined via direct wet mount following formal-ether concentration technique. Both interviewer based and self-administrated questionnaires were used to collect demographic data and factors associated with protozoan infections. Data were analyzed and computed using BM SPSS statistics version 22.0. P-value $=0.05$ at $95 \%$ confidence interval declared statistically significant. Results: Out of 418 diarrheic outpatients, the overall prevalence of protozoan infection was $59.3 \%$ (248/418). A higher percentage of intestinal protozoan infection was recorded for females $130(31.1 \%)$. Using well water as a source of drinking, poor hand washing habits before eating, not home latrine, dirty and untrimmed fingernails were the most important risk factors identified. E. histolytica complex and Giardia duodenalis were the most predominant protozoan infections detected among diarrheic outpatients.

Conclusion: The present study showed that diarrheic outpatients in the study area were heavily infected with protozoan parasitic infection. E. histolytica complex and Giardia duodenalis were the most predominant protozoans detected among diarrheic outpatients. Using well water as a source of drinking, poor handwashing habit before eating, not having home latrine, dirty and untrimmed fingernails were most important risk factors identified. So, cooperative action and health education on preventive measure are needed to reduce protozoan infections in Tigrai, particularly in the study area. The present study showed that diarrheic outpatients in the study area were heavily infected with protozoan parasitic infection.

Keywords: Adigrat, diarrhea, Ethiopia, exposure factors, intestinal protozoa, outpatients

\section{Introduction}

Protozoan infections are amongst the leading causes of morbidity and mortality throughout the world with more than 58 million diarrheal cases detected each year. ${ }^{1,2}$ However, it is difficult to estimate the actual burden of protozoan infections due to under reporting. ${ }^{3,4}$ Moreover, intestinal parasites contribute to malnutrition, protein and iron deficiencies, an increment on health costs, as well as long-term deleterious effects. ${ }^{4}$ 
Diarrheal diseases transmitted through person to person, waterborne, foodborne, and zoonotic transmissions ${ }^{2,5}$ are the major modes of transmission to humans. Giardia and Entamoeba are the major causes of acute and persistent diarrhea in humans worldwide with more pervasive in developing countries including Ethiopia. ${ }^{1,6,7}$ Giardiasis is reported to infect about 280 million people every year and contributed to 2.5 million annual deaths. Annually, an estimated 1.2 million giardiasis cases occurred in globe. ${ }^{8}$ On the other than, Amoebiasis is reported to cause an estimated 50 million cases annually with 100,000 deaths. Thus, intestinal protozoan infections are ranked second to malaria as the cause of morbidity and mortality. ${ }^{9}$

Diarrheal diseases are the second leading cause of morbidities and cause 1.8 million deaths annually, despite improved use of oral rehydration solutions, zinc, and vitamin A supplements in developing nations including Ethiopia. $^{10,11}$

Although there are other causes of diarrhea in Ethiopia, protozoan infections remain principal causes of morbidity due to socio-economic situations and poor sanitation. ${ }^{12}$ These problems are seen even if the infection intensity is mild and worse in concomitant infections. ${ }^{13}$ This may increase the prevalence of intestinal parasitic infections and needs attention. ${ }^{14}$ Epidemiology of intestinal protozoan infections among diarrheic patients in Ethiopia had been reported. However, there is a need for updating epidemiologic survey of these parasites infection at regular intervals to develop effective prevention and control strategies. Hence, this study is aimed to determine the prevalence and associated factors of protozoan infection in diarrheic outpatients in governmental health facilities of eastern Tigrai, Ethiopia and enable decision-makers' to focus on the severity of these parasitic diseases and improve factors believed to be risk for causing and transmitting of these protozoan diseases.

\section{Methods}

\section{Study Design, Period and Area}

Health facility-based cross-sectional study was conducted in all health facility of Adigrat town, Tigrai, Ethiopia from April to October 2019. The town is located around $905 \mathrm{~km}$ north of Addis Ababa (capital city of Ethiopia) at a latitude and longitude of $14^{\circ} 16^{\prime} \mathrm{N} 39^{\circ} 27^{\prime} \mathrm{E}$, with an elevation of $2457 \mathrm{~m}(8061 \mathrm{ft})$ above sea level. Based on the 2007 Census conducted by the Central Statistical Agency of Ethiopia (CSA), the town has a total population of
57,588 , people (26,010 are men and 31,578 women). The town has one General Hospital and two health centers. Currently, the Hospital is serving as a teaching hospital, emergency, inpatient and outpatients services for more than one million people who live in eastern zones of Tigrai and Afar regional state.

\section{Source Population}

All clients visiting Adigrat health facilities for health-care services.

\section{Study Participants}

All diarrheic outpatients who visited Adigrat health facilities during the study period.

\section{Exclusion Criteria}

Those patients who took medication for intestinal parasites within 1 month prior to the study, patients who were severely ill and unable to give stool sample were excluded from the study.

\section{Sample Size and Sampling Technique}

A total of 418 study participants were determined using a single population proportion formula by assuming: $95 \%$ level of confidence, $5 \%$ margin of error and $\mathrm{P}$ (proportion) of $0.453^{18}$ and non-response rate of $10 \%$. There are a total of three health institutions found in Adigrat town, namely; Adigrat hospital, Tekliswuat, and Mayda Agame health centers and the 418 study subjects were proportionally allocated to the health facilities based on the size of patient flow within 1 month prior to our study. Convenience sampling technique was employed to include the study participants.

\section{Method of Data Collection Questionnaire}

Data related demographic characteristics and factors associated with protozoan infections of the study participants were collected using both interviewers based and selfadministrated questionnaire by skilled data collectors. The questionnaires were developed from previous different published literatures and pre-tested in Wukro General Hospital.

\section{Stool Examination}

Labeled stool cup with leak-proof covers possessing respective sequential numbers were given for the study participants. Fecal specimens were carried out by wet mount and formal-ether concentration techniques. 


\section{Quality Control}

Questionnaires were pre-tested prior to the actual data collection. The collected data were checked for consistency and completeness on random bases. All the laboratory procedures were conducted as per the standard operating procedures (SOPs).

\section{Statistical Analysis}

Data were entered and analyzed using IBM SPSS statistics version 22.0. Then, it summarized using descriptive statistics. Bi-variate and multi-variate regression tests were employed to measure the association between dependent and independent variables. Variables with $\mathrm{p}<0.20$ in the bivariate logistic regression were transferred to multivariate regression analysis to compute AOR. A p-value less than 0.05 was considered statistical difference.

\section{Operational Definition}

\section{Personal Hygiene}

Study participants who did not wear foot-ware, proper working clothes, dirty and untrimmed fingernail, those who are not washing their hand before meal and after defecation and general poor looking individuals.

\section{Ethical Consideration}

Ethical clearance was taken from Research Ethical Review Committee of Adigrat University, Ethiopia. An official letter was obtained from Tigrai Regional Health Bureau to health facilities of Adigrat town. Permission was also obtained from Administrator of each health facility of Adigrat town. Furthermore, after explaining the importance of study, informed written consent were obtained from study participants. Moreover, informed written consent and assent was taken from a parent or legal guardian for participants under the age of 18 years. Additionally, this study was conducted in accordance with the declaration of Helsinki. No name was mentioned during the entire data collection and identification was based on the unique number given for each questionnaire and corresponding specimen. Confidentiality of information (results) was kept between the study participant, data collector/investigator, and authorized physician. Those study participants who have harbored any kind of intestinal parasites were reported to physician to treat.

\section{Results}

A total of 418 diarrheic outpatients were included in this study. Out of the total respondents, 214 (51.2\%) were males. The mean age of the study participants was 30 \pm 18 years, ranging 1-88 years. Majority of the study participants were in the age group of 15-24 years
(26.3\%), 1-8 education level (33\%), urban dweller (67\%) and unemployed (60.3\%) (Table 1).

\section{Prevalence of Intestinal Parasitic Infections}

The overall prevalence of intestinal protozoa infection was $59.3 \%$ (248/418) and higher infection rates were recorded among female participants $31.1 \%$ (130/418). E. histolytica complex, 39.7\% (166/418) was the predominant parasite followed by Giardia duodenalis, $11 \%$ (46/418), Taenia species and Enterobius vermicularis, $0.48 \%$ (2/418) each were also detected. The rate of multiple infections accounted for, 8.6\% (36/418) with predominant co-existent infection was $E$. histolytica complex and Giardia duodenalis, 8.1\% (34/418) (Table 2).

\section{Factors Associated with Protozoan Parasitic Infection}

Using well water as a source of drinking $(\mathrm{AOR}=3.08$, 95\% CI: $1.29-8.00, \mathrm{P}=0.021$ ), not having home latrine $(\mathrm{AOR}=1.87,95 \mathrm{CI}: 1.21-2.89, \mathrm{P}=0.04)$, had not washed their hand before meal $(\mathrm{AOR}=3.3$, 95CI: 1.42-7.90), untrimmed nails $(\mathrm{AOR}=1.71,95 \mathrm{CI}: 1.11-2.65, \mathrm{P}=$ 0.016 ) and those had dirty nail ( $\mathrm{AOR}=4.28,95 \mathrm{CI}$ : $2.73-$

Table I Demographic Characteristic of Study Participants in Governmental Health Facilities of Adigrat Town, Tigrai, Ethiopia, 2019

\begin{tabular}{|l|l|l|l|}
\hline Variables & Category & Number & Percentage \\
\hline Sex & Male & 214 & 51.2 \\
& Female & 204 & 48.8 \\
\hline Age & $<5$ & 38 & 9.1 \\
& $5-14$ & 34 & 8.1 \\
& $15-24$ & 110 & 26.3 \\
& $25-34$ & 90 & 21.5 \\
& $35-44$ & 56 & 13.4 \\
& $\geq 45$ & 90 & 21.5 \\
\hline \multirow{2}{*}{ Occupations } & Civil servant & 66 & 15.8 \\
& Self employed & 60 & 14.4 \\
& Farmer & 40 & 9.6 \\
& Unemployed & 252 & 60.3 \\
\hline \multirow{2}{*}{ Educational level } & Illiterate & 86 & 20.6 \\
& I-8 & 138 & 33 \\
& $9-12$ & 106 & 25.6 \\
& College and above & 88 & 21.1 \\
\hline \multirow{5}{*}{ Residence } & Urban & 280 & 67 \\
& Rural & 138 & 33 \\
\hline
\end{tabular}


Table 2 Distribution of Parasitic Infection by Sex and Age Among Diarrheic Patients in Governmental Health Facility of Adigrat Town, Tigrai, Ethiopia, 2019

\begin{tabular}{|c|c|c|c|c|c|c|c|c|}
\hline \multirow[t]{2}{*}{ Parasite Species } & \multicolumn{2}{|c|}{ Sex, n (\%) } & \multicolumn{6}{|c|}{ Age (Year), n (\%) } \\
\hline & Male & Female & $<5$ & $5-14$ & $15-24$ & $25-34$ & $35-44$ & $\geq 45$ \\
\hline \multicolumn{9}{|l|}{ Single infection } \\
\hline E. histolytica complex & $72(17.22)$ & $94(22.49)$ & $16(3.83)$ & $20(4.78)$ & $36(8.6 I)$ & $44(10.53)$ & $24(5.74)$ & $26(6.22)$ \\
\hline G. duodenalis & $24(5.74)$ & $22(5.26)$ & $6(1.44)$ & $4(0.96)$ & $6(1.44)$ & $4(0.96)$ & $4(0.96)$ & $22(5.26)$ \\
\hline Taenia species & $2(0.48)$ & - & - & - & $2(0.49)$ & - & - & - \\
\hline E. vermicularis & - & $2(0.48)$ & - & - & $2(0.49)$ & - & - & - \\
\hline \multicolumn{9}{|l|}{ Mixed infection } \\
\hline E.histolytica complex $+G$. duodenalis & $20(4.78)$ & $14(3.35)$ & $4(0.96)$ & $2(0.49)$ & $8(1.91)$ & $8(1.91)$ & $4(0.96)$ & $8(1.91)$ \\
\hline E. histolytica complex $+H$. nana & $2(0.48)$ & - & - & - & $2(0.49)$ & - & - & - \\
\hline
\end{tabular}

Abbreviations: E. histolytica complex, Entamoeba histolytica complex; G. duodenalis, Giardia duodenalis; E. vermicularis, Enterobius vermicularis; H.nana, Hymenolepis nana; -, missing data.

6.73, $\mathrm{P}=0.000$ ) were significant indicators of protozoan infections in the present study (Table 3).

Although not statistically associated, the prevalence of the protozoan infections was higher among those who had habits of eating raw vegetables and fruits, participants with poor personal hygiene, those who had not washed their hands after toilet and absence of regular waste disposal system.

Table 3 Factors Associated with the Occurrence of Protozoa Among Diarrheic Patients in Governmental Health Facilities of Adigrat Town, Tigrai, Ethiopia 2019

\begin{tabular}{|c|c|c|c|c|c|c|c|}
\hline \multicolumn{2}{|l|}{ Variables } & \multicolumn{2}{|c|}{ Parasite Status, n (\%) } & \multirow{3}{*}{$\begin{array}{l}\text { COR (95CI) } \\
\\
2.38(0.97-5.85) \\
0.74(0.354-1.56) \\
0.454(0.253-812)\end{array}$} & \multirow{3}{*}{$\begin{array}{l}\text { P-value } \\
\\
0.059 \\
0.430 \\
0.008\end{array}$} & \multirow{3}{*}{$\begin{array}{l}\text { AOR }(95 \mathrm{CI}) \\
1 \\
3.08(1.19-8.00) \\
0.78(0.35-3.37)\end{array}$} & \multirow{3}{*}{$\begin{array}{l}\text { P-value } \\
0.021 \\
0.546\end{array}$} \\
\hline & & \multirow{2}{*}{$\begin{array}{l}\text { Positive } \\
168(57.9) \\
8(36.4) \\
22(64.7) \\
54(75)\end{array}$} & \multirow{2}{*}{$\begin{array}{l}\text { Negative } \\
122(42.1) \\
14(63.6) \\
12(35.3) \\
18(25)\end{array}$} & & & & \\
\hline Source of drinking water & $\begin{array}{l}\text { Pipe water } \\
\text { Well water } \\
\text { River water } \\
\text { Hand pipe }\end{array}$ & & & & & & \\
\hline Presence of Latrine & $\begin{array}{l}\text { Yes } \\
\text { No }\end{array}$ & $\begin{array}{l}154(53.4) \\
98(70)\end{array}$ & $\begin{array}{l}124(46.6) \\
42(30)\end{array}$ & $1.88(1.22-2.88)$ & 0.004 & I $1.87(1.21-2.89)$ & 0.04 \\
\hline Habit of hand washing after toilet & $\begin{array}{l}\text { Yes } \\
\text { No }\end{array}$ & $\begin{array}{l}174(57.2) \\
78(68.4)\end{array}$ & $\begin{array}{l}130(42.8) \\
36(31.6)\end{array}$ & $\begin{array}{l}\text { I } \\
1.62(1.03-2.55)\end{array}$ & 0.04 & $\begin{array}{l}\text { I } \\
0.94(0.56-1.58)\end{array}$ & 0.823 \\
\hline Habit of handwashing before food & $\begin{array}{l}\text { Yes } \\
\text { No }\end{array}$ & $\begin{array}{l}238(94.4) \\
148(89.2)\end{array}$ & $\begin{array}{l}14(5.6) \\
18(10.8)\end{array}$ & $2.06(0.99-4.28)$ & 0.050 & $\begin{array}{l}\text { I } \\
3.3(1.42-7.90)\end{array}$ & 0.006 \\
\hline Habit of nail trimming & $\begin{array}{l}\text { Yes } \\
\text { No }\end{array}$ & $\begin{array}{l}112(47.5) \\
140(76.9)\end{array}$ & $\begin{array}{l}124(52.5) \\
42(23.1)\end{array}$ & $3.69(2.40-5.67)$ & 0.00 & $1.713(1.11-2.65)$ & $\begin{array}{l}1 \\
0.016\end{array}$ \\
\hline Presence of dirty nail & $\begin{array}{l}\text { Yes } \\
\text { No }\end{array}$ & $\begin{array}{l}179(75.2) \\
73(40.5)\end{array}$ & $\begin{array}{l}59(24.8) \\
107(59.5)\end{array}$ & $\begin{array}{l}4.44(2.93-6.76) \\
1\end{array}$ & 0.000 & $\begin{array}{l}4.28(2.73-6.73) \\
\text { I }\end{array}$ & 0.000 \\
\hline Eating raw vegetables & $\begin{array}{l}\text { Yes } \\
\text { No }\end{array}$ & $\begin{array}{l}134(59.8) \\
118(60.8)\end{array}$ & $\begin{array}{l}90(40.2) \\
76(39.2)\end{array}$ & $\begin{array}{l}\mathrm{I} .043(0.704-1.545) \\
\mathrm{I}\end{array}$ & 0.834 & & \\
\hline Personal hygiene & $\begin{array}{l}\text { Yes } \\
\text { No }\end{array}$ & $\begin{array}{l}164(54.3) \\
88(75.9)\end{array}$ & $\begin{array}{l}138(45.7) \\
28(24.1)\end{array}$ & $\begin{array}{l}\text { I } \\
0.804(0.49-131)\end{array}$ & 0.38 & & \\
\hline Presence waste disposal & $\begin{array}{l}\text { Yes } \\
\text { No }\end{array}$ & $\begin{array}{l}140(55.6) \\
\mid \mathrm{I} 2(67.4)\end{array}$ & $\begin{array}{l}112(44.4) \\
54(32.6)\end{array}$ & $1.66(0.93-2.956)$ & $\begin{array}{l}1 \\
0.086\end{array}$ & $1.17(0.612-2.24)$ & 0.63 \\
\hline
\end{tabular}

Note: I (referent).

Abbreviations: $\mathrm{COR}$, crude odds ratio; $\mathrm{Cl}$, confidence interval; $\mathrm{AOR}$, adjusted odds ratio. 


\section{Discussion}

Parasitic infections particularly, protozoans infections are a significant causes of diarrheal diseases at individual and public health levels in lower-income countries due to lack of safe water supply, poverty, ignorance of health promotion practices and impoverished health services. ${ }^{15-17}$ In this study, the overall prevalence of intestinal protozoan infection was $59.3 \%$. Our finding was higher than the study conducted in Ethiopia 45.3\%, ${ }^{18} 35.5 \%,{ }^{19} 41.1 \%,{ }^{20}$ $20.4 \%,{ }^{21} 10.6 \%,{ }^{22} 44.6 \%,{ }^{23}$ Iran, $30.1 \%,{ }^{24} 37.5 \%,{ }^{25}$ Ghana $42.9 \%,{ }^{26}$ Nigeria $19.3 \% .{ }^{27}$ However, it was comparable with study conducted in South Africa $68 \% .{ }^{28}$ In the other hand, our study was lower compare from study conducted in Tripoli, Lebanon $85 \%{ }^{29}$ and Nigeria 97\%. ${ }^{30}$ The variation might be due to difference in personal hygiene, population density, unavailability of potable water, socioeconomic status, poor environmental sanitation, malnutrition, health status, immunity and laboratory techniques used by different researchers. ${ }^{31-33}$

E. histolytica complex was the predominant parasitic species detected in this study with a prevalence rate of $39.7 \%$. This was higher than studies conducted from Ethiopia; $5.6 \%,{ }^{34} 10.3 \%,{ }^{35} 2.2 \%{ }^{22}$ and lower than study conducted in other parts of Ethiopia $57.5 \%,{ }^{23} 50.8 \%{ }^{19}$ This variation might be due to poor access to safe drinking water, personal hygiene, environmental sanitation, and waste disposal system as indicated in this and other study. ${ }^{18}$ Similarly, in this study, the prevalence $E$. histolytica complex is higher than studies conducted Saudi Arabia 4.7\%, ${ }^{36}$ Malaysia $0.4 \%,{ }^{37}$ Italy $4.1 \%,{ }^{38}$ Myanmar $6.2 \%,{ }^{39}$ and Iran $0.25 \%{ }^{24}$ In addition to the above variations the higher prevalence might be due to the over-diagnosis of $E$. dispar and E. moshkovskii as E.histolytica

G. duodenalis was detected among $11 \%$ of the study participants which is comparable with studies conducted in Ethiopia $11.2 \%,{ }^{18} 8.4 \%,{ }^{22}$ Iran $11 \%,{ }^{24}$ and lower than studies conducted in Ethiopia $42.4 \%,{ }^{23} 32.7 \% .{ }^{19}$ The higher prevalence of $G$. duodenalis in other part of Ethiopia this might be due to lack of access to safe drinking water, inadequacy of medical care and lower degree of sanitation. ${ }^{23}$ Likewise, the prevalence of $G$. duodenalis was lower than study conducted in Tripoli, Lebanon $28.5 \%{ }^{29}$ and higher than studies conducted in India $5 \%{ }^{40}$ and china $6.8 \%{ }^{41}$ The lower finding of $G$. duodenalis than $E$. histolytica complex in the present study might be due to the single study that can underestimate the prevalence of G. duodenalis.
Some studies have shown that males are at greater risk of developing protozoan infections ${ }^{18,24}$ and other studies indicated females were affected than males, ${ }^{42,43}$ while other studies have showed comparable prevalence. ${ }^{19,23}$ But, the present study indicated that occurrence of protozoan infections (E. histolytica complex and G. duodenalis) was higher in females than males. This is comparable with the studies conducted in Pakistan, ${ }^{44}$ Uganda, ${ }^{45}$ and Nepal. ${ }^{46}$ This might be explained due to the reason that females have increased the likelihood of soil contacts during growing vegetables and eating row vegetables than males. ${ }^{45}$

Study revealed that study participants who were using well water as a source of drinking were 3.08 times at higher risk of acquiring intestinal protozoan infections. This is parallel with previous studies. ${ }^{47,48}$ This might be contributed by the presence of resistant cysts of the parasites for routine chemical treatments like wuha agar and chlorine and the well water in the study area is unprotected; hence, it contains high number of pathogens. Similarly, those who had not washed their hands before the meal were 3.3 times at high risk of acquiring protozoan infections than those who were washing their hands before a meal. This is supported by the studies conducted elsewhere that wash their hands before meal is a significant prevention of protozoan infection. ${ }^{49-51}$ this might be due to the direct possibility of acquiring of these protozoan parasitic infections.

On the other hand, study participants who had not home latrine were 1.87 times more likely to harbor protozoan infections than those who had a home latrine. This was in agreement with studies from Ethiopia, Cotdivar and India. ${ }^{52-55}$ This might lead to open field defecation and favors the spread of intestinal parasites via faecal-oral route. ${ }^{55}$ Our study also revealed that the risk of protozoan infections was 1.71 times higher among those who had untrimmed nails and 4.28 times higher among those who had dirty nails. This is consistent with the studies. ${ }^{4-51,54-57}$ This might be due to contaminated hands and fingers can serve as a carrier for the transmission of intestinal parasitic infections. ${ }^{50,56,58-60}$

\section{Conclusions}

Findings of the present study showed that the study area was heavily infected with protozoan infections, implying that they are continued major public health problems. $E$. histolytica complex and $G$. duodenalis were the most predominant protozoans detected among diarrheic outpatients. Using well water as a source of drinking, having 
poor handwashing habit before eating, not having home latrine, having dirty and untrimmed fingernails were associated with protozoan infections. Urgent actions are needed to reduce these protozoan infections via combined approaches involving Tigrai health bureau, health extension workers, health workers and the community of the study area at large. All these bodies should plan for effective prevention and control of protozoan infections in the study area by giving awareness regarding the mode of prevention and control in the community.

\section{Limitations of the Study}

We were unable to differentiate Entamoeba histolytica from Entamoeba dispar and Entamoeba moshkovskii due to lack of molecular techniques. Other possible causes of diarrhea also not identified. Besides, this study was carried out only in symptomatic patients.

\section{Abbreviations}

CSA, Central Statistical Agency; SOPs, standard operating procedures, SPSS-Statistical product, and service solutions.

\section{Ethics Approval and Consent to Participate}

Ethical clearance was obtained from research and community service of Adigrat University. After discussing the purpose and relevance of the study, written permission was obtained from the administration of each health facility of Adigrat University before the data collection began.

\section{Data Sharing Statement}

To generate findings of this study, data were collected and analyzed based on the stated methods and materials. The original data supporting this finding will be available at any time upon reasonable request from the principal investigator.

\section{Acknowledgments}

We are thankful to laboratory professionals of Adigrat town health facilities for their cooperation in specimen collection and laboratory investigation and study participants for their willingness to participate. Besides, we are also thanks for the data collectors.

\section{Author Contributions}

BB designed the study, analyzed data \& drafted manuscript; HN, GA, FM, HL, and KT participated in the design of the study, data analysis and revision of the manuscript; HH, BT, NS, GG participated in data collection. All authors made substantial contributions to conception and design, acquisition of data, or analysis and interpretation of data; took part in drafting the article or revising it critically for important intellectual content; gave final approval of the version to be published; and agree to be accountable for all aspects of the work.

\section{Disclosure}

The authors report no conflicts of interest in this work.

\section{References}

1. Thompson RCA, Ash A. Molecular epidemiology of Giardia and Cryptosporidium infections. Infect Genet Evol. 2016;40:315-323. doi:10.1016/j.meegid.2015.09.028

2. Putignani L, Menichella D. Global distribution, public health and clinical impact of the protozoan pathogen cryptosporidium. Interdiscip Perspect Infect Dis. 2010. doi:10.1155/2010/753512

3. Kosek M, Bern C, Guerrant RL (2003). The global burden of diarrhoeal disease, as estimated from studies published between 1992 and 2000. Bulletin of the World Health Organization 2003; 81: 197-204.

4. WHO. Prevention and control of schistosomiasis and soil-transmitted helminthiasis: first report of the joint WHO expert committees. WHO Technical Report Series, 2002; 912: 1-57.

5. Pereir A, Atwill ER, Barbosa AP. Prevalence and associated risk factors for Giardia lamblia infection among children hospitalized for diarrhea in Goiania, Goias State, Brazil. Rev Inst Med Trop $S$ Paulo. 2007;49(3):139-145. doi:10.1590/S0036-46652007000 300002

6. Arapi B, Byku B, Koraqi A. Prevalence of Giardia Lamblia in children with diarrhea in Tirana. IJSR. 2016;5:11.

7. Kipchirchir KJ, Jane M, Rose O. Prevalence of cryptosporidium species and Giardia lamblia infection in patients attending Siaya district hospital. IJRMHS. 2014;4:5.

8. Kalyoussef S, Goldman D. Giardiasis and cryptosporidiosis. Pediatr Rev. 2010;31(2):81. doi:10.1542/pir.31-2-81

9. Mengestie H. Prevalence of Intestinal Parasitic Infections Among People with and Without HIV Infection and Their Association with Diarrhea in Debre Markos Town, East Gojjam Zone, Ethiopia. 2014.

10. CDC. Cryptosporidiosis and giardiasis surveillance United States, 2011-2012. MMWR Morbidity Mortality Weekly Rep. 2015;64(3).

11. Rathnayake RGL, Ranchigoda CM, Roshan RG Laboratory investigation of cryptosporidiosis and giardiasis in children with diarrhea; A hospital-based study. Proceedings of 8th International Research Conference, KDU; 2015; Srilanka.

12. Huruy K, Kassu A, Mulu A, et al. Intestinal parasitosis and shigellosis among diarrheal patients in Gondar teaching hospital, northwest Ethiopia. BMC Res Notes. 2001;4:472. doi:10.1186/1756-0500-4-472

13. Ngui R, Lim YA, Chong KL, Chuen CS, Jaffar S. Association between anemia, iron deficiency anemia, neglected parasitic infections and socioeconomic factors in rural children of West Malaysia. PLoS Negl Trop Dis. 2012;6:e1550. doi:10.1371/journal.pntd.0001550

14. Tigabu E, Petros B, Endeshaw T. Prevalence of giardiasis and cryptosporidiosis among children in relation to water sources in selected village of Pawi Special District in Benishangul-Gumuz Region, Northwestern Ethiopia. Ethiop J Health Dev. 2010;24:3.

15. Saab BR, Musharrafieh U, Nassar NT, Khogali M, Araj GF. Intestinal parasites among presumably healthy individuals in Lebanon. Saudi Med J. 2004;25:34-37. 
16. Sharif M, Daryani A, Kia E, Rezaei F, Nasiri M, Nasrolahei M Prevalence of intestinal parasites among food handlers of sari, northern Iran. Rev Inst Med Trop Sao Paulo. 2015;57(2):139-144. doi:10.1590/S0036-46652015000200007

17. Al Saqur IM, Al-Warid HS, Albahadely HS. The prevalence of Giardia lamblia and Entamoeba histolytica/dispar among Iraqi provinces. Karbala Int J Mod Sci. 2017;3:293e96. doi:10.1016/j. kijoms.2017.04.001

18. Berhe B, Bugssa G, Bayisa S, Alemu M. Foodborne intestinal protozoan infection and associated factors among patients with watery diarrhea in Northern Ethiopia; a cross-sectional study. J Health Popul Nutr. 2018;37:5. doi:10.1186/s41043-018-0137-1

19. Feleke DG, Tarko S, Hadush H, Gebretsadik D, Zenebe Y. Prevalence of intestinal parasitic infections in St. Marry Hospital, Axum, Northern Ethiopia: a retrospective study. J Trop Dis. 2017;5:235. doi:10.4172/2329-891X.1000235

20. Abebe A, Yitayal S, Gebeyaw. Opportunistic and other intestinal protozoa among HIV/AIDS patient attending Gambia higher clinic in Bahar Dar city, North West Ethiopia. Asian Pacific J Trip Med. 2011;661-665.

21. Mohammed I, Nibret E, Kibret M, Abera B, Adal M. Prevalence of diarrhea-causing protozoan infections and associated risk factors in diarrheic under-five children in Bahir Dar town, northwest Ethiopia: pediatric clinic-based study. Ethiop J Sci Technol. 2016;9(1):15-30. doi:10.4314/ejst.v9i1.2

22. Mamo H. Status of Sanitary Practices and Amebiasis and Giarrdiasis Among Patients Visiting Haik Health Center, South Wollo, Northeast Ethiopia. 2016. Unpublished.

23. Debo B. Prevalence of intestinal protozoan infection among patients in Hawassa city administration millennium health center, Ethiopia. J Appl Biotechnol Bioeng. 2018;5(4):206-210.

24. Kazemi E, Rostamkhani P, Hooshyar H. A survey on prevalence of intestinal parasites infections in patients referred to the Public Hospital in Khoy, West Azarbaijan Province, Iran, 2014-2016. Avicenna J Clin Microb Infec. 2017;4(4):e56114.

25. Kiani H, Haghighi A, Rostami A, et al. Prevalence, risk factors and symptoms associated to intestinal parasite infections among patients with gastrointestinal disorders in Nahavand, western Iran. Rev Inst Med Trop Sao Paulo. 2016;58:42. doi:10.1590/S1678-9946201658042

26. Walana W, Tay SC, Tetteh P, Ziem JB. Prevalence of intestinal protozoan infestation among primary school children in Urban and Peri-Urban Communities in Kumasi, Ghana. Sci J Public Health. 2014;2(2):52-57. doi:10.11648/j.sjph.20140202.12

27. Hassan AA, Arosoye AS, Oyebamiji DA. Survey of human intestinal parasites in communities within Ibadan, Southwestern, Nigeria. Acta Sci Microbiol. 2018;17:61-67.

28. Samie A, Guerrant RL, Barrett L, Bessong PO, Igumbor EO. Prevalence of intestinal parasitic and bacterial pathogens in diarrheal and non-diarrheal human stools from Vhembe district, South Africa. J Health Popul Nutr. 2009;27(6):739-745. doi:10.3329/jhpn.v27i6.4325

29. Osman M, El Safadi D, Cian A, et al. Prevalence and risk factors for intestinal protozoan infections with cryptosporidium, giardia, blastocystis, and dientamoeba among school children in Tripoli, Lebanon. PLoS Negl Trop Dis. 2016;10(3):e0004496. doi:10.1371/journal.pntd.0004496

30. Udeeh E, Giselle N, Popova D. The prevalence of intestinal protozoan in HIV/AIDS patient in Abuja, Nigeria. Sci World J. 2008;3(3):1-4.

31. Thapar N, Sanderson IR. Diarrhoea in children: an interface between developing and developed countries. Lancet. 2004;363 (9409):641-653. doi:10.1016/S0140-6736(04)15599-2

32. Sayyari AA, Imanzadeh F, Yazdi SA, Karami H, Yaghoobi M. Prevalence of intestinal parasitic infections in the Islamic Republic of Iran. East Mediterr Health J. 2005;11(3):377-383.

33. Raza HH, Sami RA. Epidemiological study on gastro-intestinal parasites among different sexes, occupations and age groups in Sulaimani district. J Duhok Univ. 2009;12:317-323.
34. Yami A, Mamo Y, Kebede S. Prevalence and predictors of intestinal helminthiasis among school children in Jimma zone; a cross-sectional study. Ethiopian J Health Sci. 2011;21:167-174.

35. Asrat A, Tewodros D, Alemayehu W. Prevalence and risk factors of IPs among Delgi school children, northern Gonder, Ethiopia. J Parasitol Vector Biol. 2011;3(5):75-81.

36. Zaglool DAM, Khodari YAW, Gazzaz ZJ, et al. Prevalence of intestinal parasites among patients of al-Noor specialist hospital, Makkah, Saudi Arabia. Oman Med J. 2011;26(3):182-185. doi:10.5001/omj.2011.44

37. Jamaiah I, Rohela M. Prevalence of intestinal parasites among members of the public in Kuala Lumpur, Malaysia. Southeast Asian J Trop Med Public Health. 2005;36:68-71.

38. Peruzzi S, Gorrini C, Piccolo G, Calderaro A, Dettori G. Prevalence of intestinal parasites in the area of Parma. Acta Biomed. 2006;77:147-151.

39. Prasert R, Pitak W, Nipon T. Factors associated with intestinal parasites among households in Ratchaburi province, Thai-Myanmar border area. J Trop Med Parasitol. 2008;31:85-94.

40. Daniels ME, Shrivastava A, Smith WA, Sahu P, Marion, Jenkins MW. Cryptosporidium and Giardia in humans, domestic animals, and village water sources in rural India. Am J Trop Med Hyg. 2015;93(3):596-600. doi:10.4269/ajtmh.15-0111

41. Liu H, Shen Y, Yin J, et al. Prevalence and genetic characterization of cryptosporidium, enterocytozoon, giardia and cyclospora in diarrheal outpatients in China. BMC Infect Dis. 2014;14:25. doi:10.1186/1471-2334-1425

42. Odikamnoro OO, Ikey IM The prevalence of common intestinal nematode infections among primary school children in kpirikpiri community in Abakiliki. 28th Ann conf. Niger SOC Parasitology; 2004; 20:79; Nigeria.

43. Flores JG, Esteban RAS, Mas-coma ST. Soil-transmitted helminths infection at very high altitude in Bolivia. Trans R SOC Trip Med Hug. 2001;95(3):272-277. doi:10.1016/S0035-9203(01)90232-9

44. Khan W, Nisa N, Khan A. Prevalence of potentially important intestinal pathogenic protozoan parasitic infections in different occupational groups of Swat, Pakistan. Pakistan J Zool. 2018;50 (1):123-129. doi:10.17582/journal.pjz/2018.50.1.123.129

45. Ntulume I, Tibyangye J, Aliero AA, Banson BJ. Prevalence of intestinal protozoan infections and the associated risk factors among children in Bushenyi District, Western Uganda. IJTDH. 2017;23 (2):1-9. doi:10.9734/IJTDH

46. Mukhiya RK, Rai SK, Karki AB, Prajapati A. intestinal protozoan parasitic infection among school children. J Nepal Health Res Counc. 2012;10(22):204-207.

47. Ortwer B, Ozaveshe P. Determination of some protozoan agents of diarrhoea and their relation with socio-economic factors and hygienic habits in orphanages in Benue State. J Natural Sci Res. 2015;5:23.

48. Koffi M, Djeti M, Konan T, Dje Y. Molecular characterization of intestinal protozoan parasites from children facing diarrheal disease and associated risk factors in Yamoussoukro, cote d'Ivoire. Afr J Environ Sci Technol. 2014;8(3):178-184. doi:10.5897/AJEST2013.1622

49. Andualem M. Parasitic infection and associated factors among the primary school children in Motta town, western Amhara. Ethiopia Am J Public Health Res. 2014;2(6):248-254. doi:10.12691/ajphr-2-6-6

50. Hailegebriel T. Prevalence of intestinal parasitic infections and associated risk factors among students at Dona Berber primary school, Bahir Dar, Ethiopia. BMC Infect Dis. 2017;17:362. doi:10.1186/ s12879-017-2466-x

51. Tenali RK, Badri NK, Kandati J, Ponugoti M. Prevalence of intestinal parasitic infections in cases of diarrhea among school children attending a tertiary care hospital: a two-year study. Int J Contemp Pediatr. 2018;5(3):873-878. doi:10.18203/23493291.ijcp20181505 
52. Mekonnen HS, Ekubagewargies DT. Prevalence and factors associated with intestinal parasites among under-five children attending Woreta Health Center, Northwest Ethiopia. BMC Infect Dis. 2019;19:256. doi:10.1186/s12879-019-3884-8

53. Schmidlin T, Hurlimann E, Silue KD, et al. Effects of hygiene and defecation behavior on helminths and intestinal protozoa infections in Taabo, Cote d'Ivoire. PLoS One. 2013;8(6):e65722. doi:10.1371/ journal.pone.0065722

54. Patil SR, Arnold BF, Salvatore AL, et al. The effect of india's total sanitation campaign on defecation behaviors and child health in rural Madhya Pradesh: a cluster randomized controlled trial. PLoS Med. 2014;11(8):e1001709. doi:10.1371/journal.pmed.1001709

55. Patel P, Chaudhary UK, Chudasama RK. Intestinal parasites prevalence and related factors in hospitalized children age up to 12 years with diarrhea in Surat, India. J Pediatr Sci. 2013;5:e183.

56. Mama M, Alemu G. Prevalence and factors associated with intestinal parasitic infections among food handlers of Southern Ethiopia: cross-sectional study. BMC Public Health. 2016;16:105. doi:10.1186/s12889-016-2790-x
57. Eshetu L, Dabsu R, Tadele G. Prevalence of intestinal parasites and its risk factors among food handlers in food services in Nekemte Town, West Oromia, Ethiopia. Res Rep Trop Med. 2019;10:25-30. doi:10.2147/RRTM.S186723

58. Al-Mohammed H, Amin T, Aboulmagd E, Hablus H, Zaza B. Prevalence of intestinal parasitic infections and its relationship with socio-demographic and hygienic habits among male primary school children in Al-Ahsa, Saudi Arabia. Asian Pac J Trop Med. 2010;906-912. doi:10.1016/S1995-7645(10)60218-0

59. Alemu M, Anley A, Tedla K. Magnitude of intestinal parasitosis and associated factors in rural school children, Northwest Ethiopia. Ethiop J Health Sci. 2018;29(1):923.

60. Sitotaw B, Mekuriaw H, Damtie D. Prevalence of intestinal parasitic infections and associated risk factors among Jawi primary school children, Jawi town, northwest Ethiopia. BMC Infect Dis. 2019;19:341. doi:10.1186/s12879-019-3971-x

\section{Publish your work in this journal}

Infection and Drug Resistance is an international, peer-reviewed openaccess journal that focuses on the optimal treatment of infection (bacterial, fungal and viral) and the development and institution of preventive strategies to minimize the development and spread of resistance. The journal is specifically concerned with the epidemiology of antibiotic resistance and the mechanisms of resistance development and diffusion in both hospitals and the community. The manuscript management system is completely online and includes a very quick and fair peerreview system, which is all easy to use. Visit http://www.dovepress.com/ testimonials.php to read real quotes from published authors. 